UDC 347.73:339.186

LBC 67.402 .02

\title{
THE PRINCIPLE OF RESPONSIBILITY FOR THE PERFORMANCE OF STATE AND MUNICIPAL NEEDS AS THE GOAL OF THE MONITORING AND AUDIT OF PROCUREMENT
}

\author{
Iolanta V. Baltutite \\ Volgograd State University, Volgograd, Russian Federation
}

Introduction: monitoring and auditing has become a novel contract system in the sphere of public procurement, established by the Federal law of 05.04.2013 No. 44-FZ "On contract system in procurement of goods, works, services for state and municipal needs". Methods: in order to improve the efficiency of the practical application of legal norms regulating the control over the implementation of state and municipal procurement, in addition to implementing financial and administrative controls, special attention should be paid to monitoring and audit in the field, as a final result, for financial support of public procurement is possible only if the legitimate and efficient use of funds of the respective budgets. Results: this article focuses on the issues of monitoring and auditing in the implementation of state and municipal purchases, as well as issues of responsibility of the actors of the contract system on the results of these events. Conclusions: the results of the conducted research it is established that in the Russian Federation for state and municipal needs spent a significant amount of public financial resources. The practice of application of the contract system has revealed certain weaknesses in the implementation of state (municipal) procurement in connection with this legislation established two new institutions - monitoring and auditing, aimed at checking the efficiency of use of public funds spent through this system.

Key words: contract system, customer, state and municipal procurement, the ways of state order placement, monitoring, auditing, budget.

УДК 347.73:339.186

ББК 67.402 .02

\section{СОБЛЮДЕНИЕ ПРИНЦИПА ОТВЕТСТВЕННОСТИ ЗА РЕЗУЛЬТАТИВНОСТЬ ОБЕСПЕЧЕНИЯ ГОСУДАРСТВЕННЫХ И МУНИЦИПАЛЬНЫХ НУЖД КАК ЦЕЛЬ МОНИТОРИНГА И АУДИТА ЗАКУПОК}

\author{
Иоланта Видмантовна Балтутите \\ Волгоградский государственный университет, г. Волгоград, Российская Федерация
}

\begin{abstract}
Введение: ведение мониторинга и аудита стало новеллой контрактной системы в сфере закупок, установленной Федеральным законом от 05 апреля 2013 г. № 44-Ф3 «О контрактной системе в сфере закупок товаров, работ, услуг для обеспечения государственных и муниципальных нужд». Методы: в целях повышения эффективности практического применения правовых норм, регулирующих контроль за осуществлением

$\infty$ государственных и муниципальных закупок, помимо осуществления финансового и административного 尺े контроля особое внимание необходимо уделить мониторингу и аудиту в данной сфере, поскольку конечный ๓ं результат по финансовому обеспечению государственных закупок возможен только при законном и эффективном использовании денежных средств соответствующих бюджетов. Результаты: данная статья посвящена вопросам проведения мониторинга и аудита при осуществлении государственных и муниципальных закупок, а также вопросам ответственности субъектов контрактной системы по результатам проведения указанных мероприятий. Выводы: в итоге проведенного исследования установлено, что в Российской Федерации (2) для обеспечения государственных и муниципальных нужд расходуется значительный объем публичных фи-
\end{abstract}


нансовых ресурсов. В целях экономии бюджетных средств государство создало контрактную систему в сфере закупок товаров, работ и услуг для обеспечения государственных и муниципальных нужд. Практика ее применения открыла определенные недостатки в реализации государственных (муниципальных) закупок, в связи с чем законодательством закреплены два новых института - мониторинг и аудит, имеющие целью проверку эффективности использования публичных денежных фондов, расходуемых через данную систему.

Ключевые слова: контрактная система, заказчик, государственные и муниципальные закупки, способы размещения государственного заказа, мониторинг, аудит, бюджетные средства.

\section{Введение}

В соответствии со ст. 6 Федерального закона от 05 апреля 2013 г. № 44-Ф3 «О контрактной системе в сфере закупок товаров, работ, услуг для обеспечения государственных и муниципальных нужд» (далее - Закон № 44-Ф3), контрактная система в сфере закупок основывается на ряде принципов. Речь идет о следующих принципах: открытости и прозрачности информации о контрактной системе в сфере закупок; обеспечения конкуренции; профессионализма заказчиков; стимулирования инноваций; единства контрактной системы в сфере закупок; ответственности за результативность обеспечения государственных и муниципальных нужд, эффективности осуществления закупок.

Принципу ответственности за результативность обеспечения государственных и муниципальных нужд, эффективности осуществления закупок посвящена ст. 12 Закона № 44-ФЗ. Данный принцип предполагает, что заказчики при планировании и осуществлении закупок должны исходить из необходимости достижения заданных результатов обеспечения государственных и муниципальных нужд; должностные лица заказчиков должны нести персональную ответственность за соблюдение требований, предусмотренных законодательством о контрактной системе в сфере закупок, при выявлении нарушений, установленных в результате проведенного контроля, аудита и мониторинга.

\section{Мониторинг в контрактной системе}

Важной особенностью Закона № 44-Ф3 стало введение институтов мониторинга и аудита закупок, которые имеют своей целью проверку и оценку информации об осуществленных закупках, выявление возможных нарушений и впоследствии привлечение субъектов контрактной системы к ответственности.
Все эти нововведения неслучайны и происходят по причине интеграции России в единое европейское экономическое пространство, в результате чего происходит постепенное сближениеправового регулирования приоритетных сфер жизнедеятельности сторон и соответствующих отраслей права, среди которых первое место отведено предприятиям и предпринимательской деятельности [4, с. 98]. На основании ч. 1 ст. 97 Закона № 44-Ф3 мониторинг представляет собой особую систему постоянных наблюдений в сфере закупок посредством сбора, обобщения, систематизации и оценки информации об осуществлении закупок, в том числе реализации планов закупок и планов-графиков. Осуществлять мониторинг закупок уполномочен федеральный орган исполнительной власти по регулированию контрактной системы, которым Постановлением Правительства РФ от 26 августа 2013 г. № 728 определено Минэкономразвития России.

Правила мониторинга закупок утверждены Постановлением Правительства РФ от 03 ноября 2015 г. № 1193, которое вступило в силу с 01 января 2017 года. В частности, данными правилами (п. 3) утверждены источники информации, которые подлежат мониторингу. К ним относятся:

a) сведения об осуществлении закупок, включая реализацию планов закупок и плановграфиков закупок, размещенных в ЕИС;

б) сведения, поступающие в Минэкономразвития России от Федерального казначейства (количество и сумма закупок, не размещенных в ЕИС, с разбивкой по источникам финансирования; закрытый реестр банковских гарантий) и от ФАС России (количество обращений о включении информации в реестр недобросовестных поставщиков и результаты их рассмотрения, о согласовании закрытых способов определения поставщиков, о заключении контракта с единственным поставщиком в соответствии с Законом № 44-Ф3); 
в) сведения, содержащиеся в письмах и обращениях, поступающих в адрес Минэкономразвития России;

г) сведения о вступивших в законную силу судебных актах по вопросам осуществления закупок; ников.

д) другие сведения из открытых источ-

На основании п. 5 правил в ходе мониторинга оценка должна проводиться по следующим критериям:

а) степень достижения целей осуществления закупок, которые определяются на основании ст. 13 Закона № 44-Ф3;

б) обоснованность закупок, определяемая на основании ст. 18 Закона № 44-Ф3;

в) необходимость совершенствования законодательства РФ и других нормативноправовых актов о контрактной системе в сфере закупок;

г) эффективность обеспечения государственных и муниципальных нужд (для чего подлежит утверждению специальная методика).

В силу ч. 5 ст. 97 Закона № 44-Ф3, итогом мониторинга должен являться сводный аналитический отчет, который представляется Минэкономразвития России в Правительство Российской Федерации.

На региональном уровне могут устанавливаться свои показатели, по которым должен проводиться мониторинг закупок.

Так, в Тульской области были определены показатели результативности выполнения мероприятий в сфере госзакупок:

1) исполнение плана-графика;

2) доля конкурентных способов определения поставщика в общем объеме закупок;

3) доля объявленных закупок на сумму более 100 млн руб., прошедших общественное обсуждение;

4) достижение повышенных показателей закупок у субъектов малого предпринимательства.

Для более подробного анализа деятельности заказчиков, а также с учетом перспективного введения оценки финансового менеджмента было принято решение о дополнительных показателях, которые следует мониторить с использованием региональной информационной системы в сфере закупок:
- эффективность планирования (каков объем закупок на средства текущего финансового года, включенных в планы-графики на очередной финансовый год, от совокупного годового объема закупок, за исключением закупок, осуществленных в предыдущем финансовом году (годах));

- нормирование закупок (какова доля закупок, запланированных с учетом требования ст. 19 Закона № 44-Ф3, от общего объема закупок);

- экономическая эффективность обоснования НМЦК (среднее снижение НМЦК);

- эффективность предоставления преференций субъектам малого предпринимательства и социально ориентированным некоммерческим организациям (объем закупок, осуществленных у данных субъектов);

- эффективность ведения претензионной работы (объем контрактов, по которым исполнителем просрочено исполнение обязательств, а заказчиком не предъявлены претензии) [2, с. 87].

\section{Аудит в контрактной системе закупок}

Аудит представляет собой независимую проверку бухгалтерской отчетности (ч. 3 ст. 1 Федерального закона от 30 декабря 2008 г. № 307-Ф3 «Об аудиторской деятельности»). Как отмечает В.П. Гринев, аудит осуществляется «Счетной палатой РФ, контрольносчетными органами субъектов РФ, образованными законодательными (представительными) органами государственной власти субъектов РФ, и контрольно-счетными органами муниципальных образований (в случае, если такие органы образованы в муниципальных образованиях), образованными представительными органами муниципальных образований» [3, c. 43].

Законом предусмотрены различные виды ответственности за нарушение законодательства РФ и иных нормативных правовых актов о контрактной системе в сфере закупок.

Лица, виновные в нарушении законодательства РФ и иных нормативных правовых актов о контрактной системе в сфере закупок, несут дисциплинарную, гражданско-правовую, административную и уголовную от- 
ветственность в соответствии с российским законодательством (ч. 1 ст. 107 Закона № 44-Ф3).

Должностные лица заказчиков несут за свои действия (бездействие), в том числе за недостижение запланированных результатов процедур закупок для государственных и муниципальных нужд, персональную ответственность (ст. 12 закона № 44-Ф3). На практике персональная ответственность чаще всего связывается с юридической ответственностью за невыполнение (ненадлежащее выполнение) соответствующих обязанностей (ст. 107 Закона № 44-Ф3). Хотя соответствующие должностные лица Минэкономразвития России еще на стадии обсуждения законопроекта о федеральной контрактной системе отмечали, что ответственность в данной сфере не сводится исключительно к юридической. «Когда мы говорим об ответственности как принципе - это также полнота и достаточность мер и действий, предпринятых должностным лицом, содержательность его закупочных решений. Закон о федеральной контрактной системе устанавливает субъективную обязанность отвечать за поступки и действия, а также за их последствия. Мерой выступает не срыв контракта, а успех. Нам кажется, важна позитивность этой статьи» $[1$, с. 56].

В случае признания планируемой закупки необоснованной органы контроля и аудита выдают предписания об устранении выявленных нарушений законодательства РФ и иных нормативных правовых актов о контрактной системе в сфере закупок и привлекают к административной ответственности лиц, виновных в нарушениях требований закона, в порядке, установленном КоАП РФ (п. 6 ст. 12).

Ответственность заказчиков при проведении совместных конкурсов или аукционов определяется соглашением сторон, заключенным в соответствии с ГК РФ и законом о контрактной системе (п. 1 ст. 25).

Аудиторы Счетной палаты самостоятельно организуют аудит и несут ответственность за результаты. Цель такого аудита состоит в оценке обоснованности планирования, реализуемости и эффективности закупок, оценке результатов закупок, анализе достижения целей, намеченных в государственных и межгосударственных целевых программах; в ис- полнении международных обязательств страны. Контрольные мероприятия оценивают деятельность заказчиков, контрактных служб и комиссий, экспертных организаций, работу ведомственного контроля.

Итог аудита - оценка уровня обеспечения государственных нужд из бюджетных средств. Оценивают выполнение контрактов относительно сроков, объемов, цен контрактов, количества и качества приобретаемых товаров, работ и услуг, в том числе порядка ценообразования и эффективности системы управления контрактами. Аудиту подлежат планирование закупок товаров (работ, услуг), осуществление закупок, заключение и исполнение контракта. В ходе проведения аудита проверяют использование бюджетных средств (федерального бюджета, государственных внебюджетных фондов, региональных, муниципальных). Аудиту подлежат следующие организации: государственные органы, бюджетные учреждения, автономные учреждения, государственные унитарные предприятия, юридические лица.

Согласно ч. 2 ст. 98 Закона № 44-Ф3, органы аудита в сфере закупок осуществляют:

1) анализ деятельности участников отношений в сфере обеспечения закупок для государственных и муниципальных нужд;

2) оценку результатов действий участников отношений в сфере обеспечения закупок для государственных и муниципальных нужд.

При этом указанные анализ и оценка осуществляются на предмет соответствия целям осуществления закупок, обозначенным в ст. 13 Закона № 44-Ф3.

Согласно ч. 3 ст. 98 Закона № 44-Ф3, Счетная палата РФ, контрольно-счетные органы субъектов РФ и контрольно-счетные органы муниципальных образований вправе осуществлять контрольную, экспертно-аналитическую, информационную и иные виды деятельности. Контрольная и экспертно-аналитическая деятельность Счетной палаты РФ заключается в проведении контрольных и экспертно-аналитических мероприятий, представляющих собой:

- финансовый аудит (контроль) - проверка ведения учета и правильности формирования отчетности по заключенным контрактам; 
- аудит эффективности - оценка результатов контракта с позиций эффективности, результативности, экономичности с учетом требований к качеству поставленной номенклатуры;

- комплаенс-аудит - проверка обоснованности, законности заключения государственных контрактов и соблюдения обозначенных в них условий;

- иные виды аудита.

При этом с точки зрения времени проведения проверки аудит может быть как предварительным, так и последующим. На данный момент в отечественной практике лучше отработаны технологии последующего аудита, в то время как технологии предварительного аудита практически не используются. Между тем последний представляет собой достаточно эффективный способ превентивного контроля, поскольку позволяет сразу же наложить определенные санкции - выдать отказ от санкционирования контракта в случае бухгалтерских и правовых нарушений.

По результатам деятельности, обозначенной в ч. 3 ст. 98 Закона № 44-ФЗ, органы аудита в сфере закупок обобщают результаты осуществления этой деятельности, в том числе:

1) устанавливают причины выявленных отклонений, нарушений и недостатков. В частности, необходимо указать общее количество нарушений законодательства в сфере закупок относительно законности, эффективности, результативности расходов на закупки по планируемым к заключению, заключенным и исполненным контрактам, в том числе сумму нарушений, общую стоимость контрактов. В случае выявления нарушений, содержащих признаки административных правонарушений (ст.ст. 7.29, 7.30, 7.32 КоАП РФ), после утверждения отчета о результатах контрольного мероприятия информация и материалы направляются Счетной палатой РФ в соответствующие правоохранительные органы для принятия мер реагирования;

2) подготавливают конкретные предложения, направленные на устранение выявленных отклонений, нарушений и недостатков, а также на совершенствование контрактной системы в сфере закупок. В частности, контрольная группа вправе рекомендовать орга- низации провести переподготовку (повышение квалификации) должностных лиц, имеющих отношение к контрактной системе в сфере закупок;

3) систематизируют информацию о реализации указанных предложений и размещают на официальном сайте РФ в сети Интернет обобщенную информацию о таких результатах.

Для решения поставленных задач и реализации возложенных законом полномочий по проведению контрактного аудита в Счетной палате РФ разработан и активно используется ряд внутренних стандартов, регламентов, инструкций и положений. Указанные документы имеют статус обязательных для исполнения и в значительной мере определяют работу по проведению контрактного аудита. Следует отметить, что сложившаяся система внутренних документов не является устоявшейся и находится в постоянном изменении и доработке. В настоящий момент ее можно охарактеризовать следующим образом:

- общие правила деятельности Счетной палаты (9 стандартов);

- стандарты отчетности Счетной палаты (1 стандарт);

- специальные (2 стандарта);

- внешний аудит федерального бюджета и бюджетов государственных внебюджетных фондов (5 стандартов);

- качество контрольных стандартов (1 стандарт);

- взаимодействие с другими органами (1 стандарт);

- проведение типов контрольных мероприятий (1 стандарт) [5, с. 83].

В рамках методологического обеспечения осуществления контрольных мероприятий в сфере государственных закупок в 2014 г. коллегией Счетной палаты РФ утверждены методические рекомендации по проведению аудита в сфере закупок. Данные рекомендации дают подробную схему аудиторской проверки, определяя и конкретизируя некоторые процедурные вопросы. В них представлен перечень вопросов, рассматриваемых в ходе аудита, и даны некоторые подходы к осуществлению аудиторской проверки. В качестве основного рассматривается вопрос правильного выполнения всей совокупности закупочных процедур, предусмотренных Законом № 44-ФЗ. 
В соответствии с методическими рекомендациями проверке подлежат законность, своевременность и результативность осуществляемых закупок и соблюдение сторонами положений заключенного контракта. При этом основной упор делается на вопросы оценки целесообразности и эффективности осуществленных закупок, соблюдения принципа ответственности за результативность закупок, что является отличительной чертой контрактного аудита.

\section{Выводы}

Подводя итог изложенному, следует особо подчеркнуть, что введение института мониторинга в перспективе должно благотворно сказаться на развитии единой контрактной системы закупок в РФ, а также на процессе расходования бюджетных средств государства и муниципалитетов, поскольку планомерный анализ практики применения законодательства о контрактной системе позволит в будущем выявить ее недостатки, определить основные проблемы ее практического применения, сформулировать часто совершаемые ошибки со стороны участников государственных (муниципальных) закупок.

Контрактный аудит - новое направление внешнего государственного финансового контроля. Его ключевые понятия, определения, цели и задачи на данный момент четко не определены, а используемый понятийный аппарат нуждается в уточнении и развитии. Однако работа в этом направлении ведется активно, и одним из ее направлений является уточнение и совершенствование правового обеспечения контрактного аудита, в том числе в области разработки внутреннего стандарта государственного финансового контроля. Успешное решение этой задачи позволит поднять эффективность государственных закупок, способствуя повышению надежности и прозрачности бюджетных отношений в целом.

Контрольная деятельность органов аудита в сфере государственных закупок является очень важной, она направлена на повышение эффективности функционирования системы перераспределения общенациональных ресурсов, а также на снижение коррупционных рисков. Эффективность расходования финансовых ресурсов должна опреде- ляться путем тщательной организации аналитической работы, а также систематизации нарушений, которые выявляют все контролирующие органы.

\section{СПИСОК ЛИТЕРАТУРЫ}

1. Белов, В. Е. Принцип ответственности за результативность обеспечения государственных и муниципальных нужд, эффективность осуществления закупок: Содержание и реализация / В. Е. Белов // Публичные закупки: проблемы правоприменения : материалы Второй Всерос. науч.-практ. конф. (6 июня 2014 г., МГУ им. М.В. Ломоносова). - М., 2014. - C. 56.

2. Гремякова, О. П. Конечная цель - полная автоматизация закупочного процесса / О. П. Гремякова // Бюджет. - 2015. - № 9. - С. 87.

3. Гринев, В. П. Контрактная система как механизм нормоконтроля расходования бюджетных средств / В. П. Гринев // Право и экономика. -2015 . № 7. - C. 43.

4. Иншакова, А. О. Новые формы хозяйствования как слагаемые успеха интеграции РФ в единое экономическое пространство с ЕС / А. О. Иншакова // Право и государство: теория и практика. - 2010. - № 10 (70), - С. 98-104.

5. Ткаченко, Д. П. Правовые основы контрактного аудита / Д. П. Ткаченко, В. Л. Кожухов // Аудитор. - 2015. - № 3. - С. 83.

\section{REFERENCES}

1. Belov V.E. Printsip otvetstvennosti za rezultativnost obespecheniya gosudarstvennykh i munitsipalnykh nuzhd, effektivnost osushchestvleniya zakupok: Soderzhanie i realizatsiya [The Principle of Responsibility for the Performance of State and Municipal Needs, Efficiency of Procurement: Essence and Enforcement]. Publichnye zakupki: problemy pravoprimeneniya. Materialy Vtoroy Vseros. nauch.prakt. konf. (6 iyunya $2014 \mathrm{~g}$., MGU im. M.V. Lomonosova) [Public Procurement: Issues of Enforcement. Proceedings of the Second All-Russian Scientific-Practical Conference (June 6, 2014, Moscow State University named after M.V. Lomonosov)]. Moscow, 2014, p. 56.

2. Gremyakov O.P. Konechnaya tsel - polnaya avtomatizatsiya zakupochnogo protsessa [The Ultimate Goal Is Full Automation of the Procurement Process]. Byudzhet, 2015, no. 9, p. 87.

3. Grinev V.P. Kontraktnaya sistema kak mekhanizm normokontrolya raskhodovaniya byudzhetnykh sredstv [Contract System as a 
И.В. Балтутите. Ответственность за результативность обеспечения государственных и муниципальных нужд

Mechanism for Control of Budget Spending]. Pravo $i$ ekonomika, 2015, no. 7, p. 43.

4. Inshakova A.O. Novye formy khozyaystvovaniya kak slagaemye uspekha integratsii RF v edinoe ekonomicheskoe prostranstvo s ES [The New Forms of Management as a Factor of Success of
Russia's Integration into the Common Economic Space with the EU]. Pravo i gosudarstvo: teoriya i praktika, 2010, no. 10 (70), pp. 98-104.

5. Tkachenko D.P., Kozhukhov V.L. Pravovye osnovy kontraktnogo audita [The Legal Basis of the Contract Audit]. Auditor, 2015, no. 3, p. 83.

\section{Information about the Author}

Iolanta V. Baltutite, Candidate of Juridical Sciences, Associate Professor, Department of Civil and International Private Law, Volgograd State University, Base Department of the Southern Scientific Center of the Russian Academy of Sciences, Prosp. Universitetsky, 100, 400062 Volgograd, Russian Federation,u938om@yandex.ru.

\section{Информация об авторе}

Иоланта Видмантовна Балтутите, кандидат юридических наук, доцент кафедры гражданского и международного частного права, Волгоградский государственный университет, базовая кафедра ЮНЦ РАН, просп. Университетский, 100, 400062 г. Волгоград, Российская Федерация, u938om@yandex.ru. 